\title{
CAREER SUCCESS SCHEMAS AND THEIR CONTEXTUAL EMBEDDEDNESS: A COMPARATIVE CONFIGURATIONAL PERSPECTIVE
}

Keywords: subjective career success, schemas, cognitive mapping, configurational approach, institutional context, taxonomy, QCA.

Dr. Robert Kaše (corresponding author) University of Ljubljana, Faculty of Economics Kardeljeva ploscad 17, 1000 Ljubljana, Slovenia Phone: +38615892469 e-mail: robert.kase@ef.uni-lj.si

Dr. Nicky Dries

KU Leuven, Faculty of Economics and Business Naamsestraat 69, 3000 Leuven, Belgium Phone: +3216373719 e-mail: nicky.dries@kuleuven.be

Prof. Jon Briscoe Northern Illinois University, Department of Management Barsema Hall 245h, DeKalb, IL 60178 Phone: 1(815)793-4041 e-mail: jonbriscoe@niu.edu Dr. Richard D. Cotton University of Victoria, Gustavson School of Business PO Box 1700 STN CSC, Victoria, BC, V8W 2Y2 Canada Phone: +1 250-721-8052 
e-mail: rcotton@uvic.ca

Dr. Eleni Apospori

Athens University of Economics and Business, Department of Marketing and Communication Patission 76, Athens 10434, Greece

Phone: +302108203141

e-mail: apospori@aueb.gr

\author{
Dr. Silvia Bagdadli \\ Bocconi University, Department of Management and Technology \\ Via Rontgen 1, 20136 Milan, Italy \\ Phone: +393356813513 \\ e-mail: $\underline{\text { silvia.bagdadli@unibocconi.it }}$
}

Dr. K. Övgü Çakmak-Otluoğlu

Istanbul University, School of Business, Department of Human Resource Management, 34320 Avcilar, Istanbul, Turkey.

Phone: +902124737070

e-mail: ovgu@,istanbul.edu.tr

Dr. Katharina Chudzikowski

School of Management, University of Bath

Claverton Down, BA2 7AY, Bath, United Kingdom

Phone: + 44 (0) 1225383499

e-mail: k.chudzikowski@bath.ac.uk 
Prof. Anders Dysvik

Department of Leadership and Organizational Behaviour, BI Norwegian Business School Nydalsveien 37, 0484 Oslo, NO-0442 Oslo, Norway

Phone: +4746410713

e-mail: anders.dysvik@,bi.no

Dr. Martina Gianecchini

University of Padova, Department of Economics and Management

via del Santo 33, 35123 Padova, Italy

Phone: +390498273847

e-mail: martina.gianecchini@unipd.it

Prof. Richa Saxena

HR \& OB Area, Institute of Management Technology Ghaziabad

Raj Nagar, Post Box No. 137, Ghaziabad (INDIA) 201001

e-mail: $\underline{\text { rsaxena@imt.edu }}$

Dr. Yan Shen

University of Victoria, Gustavson School of Business

PO Box 1700 STN CSC, Victoria, BC, V8W 2Y2 Canada

Phone: +1 250-721-6312

e-mail:yanshen@uvic.ca

Dr. Marijke Verbruggen

University of Leuven, Faculty of Economics and Business

Naamsestraat 69, 3000 Leuven, Belgium

Phone: +3216326869 
e-mail: marijke.verbruggen@kuleuven.be

\author{
Dr Ifedapo Adeleye \\ University of Tennessee, Haslam College of Business \\ 1000 Volunteer Boulevard, Knoxville, TN 37996 USA \\ Phone: 865-974-1521 \\ e-mail: iadeleye@utk.edu \\ Olusegun Babalola \\ Lagos Business School, Pan-Atlantic University \\ Km 22 Lekki-Epe Expressway, Ajah - Lagos, Nigeria \\ Phone:+2347082047004 \\ e-mail: segunolababalola@gmail.com
}

Prof. Tania Casado

University of São Paulo, Faculty of Economics, Business Administration and Accountancy Av. Prof. Luciano Gualberto, 908. São Paulo, SP. Brazil

Phone: +551130915909
e-mail: tcasado@usp.br

Prof. Jean-Luc Cerdin

ESSEC Business School

Av. Bernard Hirsch, B.P. 50105, 95021 Cergy Pontoise Cedex, France

Phone:

e-mail: cerdin@essec.fr

Dr. Najung Kim

Kookmin University, College of Business Administration 
Seongbuk-Gu Jeongreung-ro 77, Seoul, South Korea 02707

Phone: +8229105763

e-mail: najungkim@kookmin.ac.kr

Dr. Sushanta Kumar Mishra

Indian Institute of Management Indore

Rau-Pithampur road, Indore Madhya Pradesh, 453331, India

Phone: $+91-7312439520$

e-mail: sushantam@iimidr.ac.in

\author{
Dr. Julie Unite
}

Humber, Mundie, and McClary

111 E. Wisconsin Ave, Suite 1700, Milwaukee, WI 53202-4889, USA

Phone: +1 414 271-6220

e-mail: junite@humbermm.com

Dr. Fei Zhangfeng

DongHua University, Faculty of Business Administration

1882, Yanan Road (west), Shanghai, China

Phone: +862162373889

e-mail: fzhf@dhu.edu.cn

*The authors have no conflict of interest.

**No funding was received to support this research.

***The authors do not want to add acknowledgements. 


\title{
CAREER SUCCESS SCHEMAS AND THEIR CONTEXTUAL EMBEDDEDNESS: A COMPARATIVE CONFIGURATIONAL PERSPECTIVE
}

\begin{abstract}
We introduce career success schemas as critical for understanding how people in different contexts perceive and understand career success. Using a comparative configurational approach, we show, in a study of thirteen countries, that two structural characteristics of career success schemas - complexity and convergence-differ across country contexts and are embedded in specific configurations of institutional factors. Adopting complexity and convergence as primary dimensions, we propose a taxonomy of career success schemas at the country level. Based on this taxonomy, we contribute to the understanding of subjective career success across countries, discuss the importance of schemas for organizational career systems in MNEs, and propose specific guidelines for future comparative careers research.
\end{abstract}

Keywords: subjective career success, schemas, cognitive mapping, configurational approach, institutional context, taxonomy, QCA. 
The traditional approach to career development, from a human resource management (HRM) perspective, has been to support employees in reaching their career goals through HR practices such as mentoring and personal development plans (Baruch \& Peiperl, 2000). Organizational career management — always to some extent bound by the career paths available to employees in a given organization - has therefore focused on helping employees obtain promotions, pay raises, and transition into leadership positions (Stumpf, Doh, \& Tymon, 2010). Although both the HRM and careers literatures have in recent years acknowledged that career success has evolved into a concept broader than pay, promotions, and status alone, there has been little integration of these insights into the HRM literature (Kraimer, Seibert, Wayne, Liden, \& Bravo, 2011; Mayrhofer, Meyer, Iellatchitch, \& Schiffinger, 2004).

More specifically, it is unclear to what extent and in what ways the contemporary, more subjectivist approach to career success (i.e., "how people feel about their work experience" [Gunz \& Heslin, 2005: 106] encompassing “individuals' subjective judgments about career attainments, such as job and career satisfaction" $[\mathrm{Ng}$, Eby, Sorensen, \& Feldman, 2005: 368-369]) may or may not correspond to the more objectivist approach to career success focused on "outwardly visible manifestations of success" (Gunz \& Heslin, 2005: 106). Better understanding the cognitions that individuals bring to career success thus may have important implications for career management in organizations, especially in multinational enterprises (MNEs) operating in diverse cultures (Caligiuri, Lepak, \& Bonache, 2010).

An important challenge for MNEs then is understanding how career success is seen and understood across different country contexts. The scant literature on country-level differences in career management systems has distinguished Latin, Germanic, Anglo-Dutch, and Japanese career systems in MNEs (Evans, Pucik, \& Barsoux, 2002) and established that 
each of these socializes employees into a highly specific understanding of how to pursue a successful career. More recent scholarly work has focused on 'clashes' between countryspecific career systems, and emphasizes the wider acknowledgement of the pivotal impact of institutional factors on cross-cultural career management in MNEs (cf. Al Ariss, 2010; Boussebaa \& Morgan, 2008; Englehardt, 2011).

At the same time - inspired by calls for a more subjectivist understanding of career success (Gunz \& Heslin, 2005)—careers researchers have recently developed multidimensional models and scales ahereing to the logic that subjective career success can (or should) be represented using several dimensions (e.g., Shockley, Ureksoy, Rodopman, Poteat, \& Dullaghan, 2016). These new models and scales allow HR researchers and practitioners to asess how different (groups of) people define career success, and thus represent a more comprehensive approach to understanding career success. As a result, the subjectivist, multidimensional approach to career success has been attributed great potential for better understanding how people from different countries and cultures see and experience career success.

That said, researchers studying the relationship between culture and cognition have concluded, after decades of research, that people across the globe see the world in fundamentally different ways (cf. Nisbett, Peng, Choi, \& Norenzayan, 2001). Specifically, Western people have a tendency to develop context-independent, rules-based, and highly clustered schemas - defined as internalized cognitive representations of knowledge that gradually develop from experience, and subsequently guide the way new information is organized and interpreted (Rousseau, 2001; Winn \& Snyder, 1996)—while Eastern people tend to hold more context-dependent, 'holistic' schemas in which relationships between schema 'elements' (i.e., meanings), rather than the differences between them, are emphasized (Nisbett \& Miyamoto, 2005). Put simply, although the subjectivist approach to career success 
is a promising move away from the more normative, traditional view of careers, the recent focus on identifying sets of distinct, independent factors of career success meanings may in fact represent another type of Western bias - the tendency to 'split' constructs into discrete categories (Zerubavel, 1996).

Therefore, if we want to understand the meaning of career success across countries, we first need to understand how people in different countries see and understand career success per se; that is, how they cognitively organize a network of meanings attributed to career success (Rousseau, 2001). In this paper we propose that a true 'decentered' (Leung, 2008) understanding of career success requires knowing the underlying structural characteristics of career success schemas, and how these relate to specific institutional and cultural socialization mechanisms in a country (Weber \& Glynn, 2006). To this end, we introduce and focus on schema complexity and convergence, two robust, generally applicable structural characteristics of cognitive schemas. They address the amount of within-person schema nuance (i.e., complexity) (Zerubavel, 1996) and between-person schema consensus (i.e., convergence) (Jonker, van Riemsdijk, \& Vermeulen, 2011) respectively, which we also found salient for examining similarities and differences in the cognitions of career success meanings.

In this paper, we first conceptualize career success schemas, and align the two structural characteristics of complexity and convergence accordingly. We then adopt a configurational logic in identifying a set of institutional factors and key contextual mechanisms in the formation of these schemas. The emphasis here is on configurations of factors rather than on individual institutional factors alone since, due to the complex interplay of contextual factors in shaping career success schemas, configurations should enable more robust contextual nuance (Johns, 2006). This configurational logic is reflected in our study design. We start with cognitive mapping of career success schemas of individual respondents 
from thirteen countries, establishing aggregate complexity and convergence scores for each country, and developing a taxonomy of country-level career success schemas. Subsequently, we use qualitative comparative analysis (QCA) to derive the configurations of contextual factors that shape career success schema complexity and convergence at the country level.

Taken together, our research points toward the need for a more fine-grained and nuanced consideration of context in our understanding of career success schemas, as a foundation for understanding subjective career success across national cultures, and particularly its implications for career management systems in MNEs (Tomlinson, Baird, Berg, \& Cooper, 2018). More specifically, we contribute to the international HRM literature in three ways. First, we introduce the construct 'career success schema' and its structural characteristics, both at the individual and collective (i.e., shared) level. Second, we identify four career success schema archetypes based on the two dimensions, complexity and convergence, which allow the classification of countries into a schema-based taxonomy of career success. Finally, we identify configurations of the institutional factors and contextual mechanisms that shape career success schemas at the country level.

\section{STRUCTURAL CHARACTERISTICS OF CAREER SUCCESS SCHEMAS}

A schema is an organized structure that exists in memory (Palmer \& Pickett, 1999), and that, together with all other schemas held by a given individual, represents his or her full knowledge of the world (Winn \& Snyder, 1996). Schemas are abstract, internalized cognitive representations of knowledge, amenable to change in line with the individual's life experiences. They provide a filter for the interpretation of new information, and in so doing result in cognitive efficiency. It is difficult to imagine having to reinterpret daily phenomena without being able to rely on schema-based memory (Spicer, 1998; Palmer \& Pickett, 1999). Although schemas are only representations of declarative knowledge on the 'what' of a phenomenon (Palmer \& Pickett, 1999), people use them as a foundational basis for reasoning, 
making predictions and decisions about the specific life domain represented by them (Jones, Ross, Lynam, Perez, \& Leitch, 2011).

Career success schemas, in particular, can be defined as networked structures of subjective career success meanings (including facets such as achieving wealth, outperforming others, having good work-life balance, countinously learning, becoming a better person, etc.) that guide people's interpretations of their career experiences and subsequently, their career decisions and behaviors (cf. Rousseau, 2001). Research in the field of careers has found that perceptions of career opportunities resulting from internal labour market practices create expectations and a frame of reference for one's own expected future career success (e.g., Aryee, Chay, \& Tan, 1994; Judge, Cable, Boudreau, \& Bretz, 1995). While past success experiences feed into career success schemas and result in favorable projections of future career prospects (Eby, Durley, Evans, \& Ragins, 2006), career insecurities and concerns translate into reduced career-related self-efficacy and thus a narrower cognitive representation of what constitutes the 'conceivable' (Gabriel, Gray, \& Goregaokar, 2010).

It is important to note that career opportunities and constraints not only occur at the individual level, but also at the level of societies and labor markets (Weber \& Glynn, 2006). We need only imagine what 'career success' might mean to recent graduates in Spain and Greece—where economic turmoil and extremely high levels of youth unemployment have been rampant for years - compared to what it might mean to STEM graduates in the US, where a million job openings are expected between 2014 and 2024 (Fayer, Lacey, \& Watson, 2017). As this illustration suggests, career success schemas can only truly be understood in context (Tomlinson, Baird, Berg, \& Cooper, 2018; Johns, 2006).

In order to add context and make the conceptual and methodological leap from individually to collectively held schemas, we analyze career success schemas along two structural dimensions: schema complexity and schema convergence. In academic research, 
schemas are commonly visualized as networks (also called cognitive maps; Carley \& Palmquist, 1992). Within these networks of interrelated concepts 'islands of meaning' are created - clusters of meanings that are more similar to one another than to meanings outside of each cluster (Borgatti \& Halgin, 2011). Carving out such clusters within a schema requires the simultaneous operation of the two diametrically opposed cognitive acts of assimilation (or 'lumping') and differentiation (or 'splitting'). Lumping refers to the (intracategorical) grouping of similar meanings together in a single mental cluster, whereas splitting refers to the (intercategorical) separation of different meanings into different mental clusters (Zerubavel, 1996).

Schema complexity thus refers to the extent to which an individual or members of a given social group (for instance, a country) collectivelly have a tendency for lumping or splitting (Furlow, 2003). It is believed to depend on the level of experience people from that social group have with the subject of the schema, as well as on its institutional and cultural socialization mechanisms (Conway et al., 2001; Fassin et al., 2015). Rousseau (2001), for example, notes that occupational schemas among people in those occupations contain more elements compared to laymen's schemas of these occupations (e.g., non-academics seeing professors primarily as 'teachers').

While schema complexity refers to the number of meanings and the number of relationships between meanings, schema convergence refers to the degree to which people belonging to a given social group (for instance, a country) group schema elements (for instance, career success meanings) together in a similar way (Moussavi \& Evans, 1993). Although the term convergence implies full similarity between two or more people's schemas - similarity being defined as schemas containing much of the same meanings and/or similar relationships between meanings (Liu, Friedman, Barry, Gelfand, \& Zhang, 2012) this is typically not the case. Rather, a threshold of similarity needs to be met in order for 
shared schemas to be interpretable (Jonker et al., 2010). Career success schema convergence is typically achieved through institutionalized socialization mechanisms that transform private, idiosyncratic representations into public, shared representations (Schaller \& Crandall, 2003). Highly convergent career success schemas thus imply that people in a country tend to agree on which specific career success meanings belong to the same cluster, whereas weakly convergent career success schemas imply that people in a country differ substantially in terms of which career success meanings they group together and how. Subsequently, the more convergent people's career success schemas in a given country, the more appropriate it becomes to talk about a 'shared' career success schema, and to interpret that country's collective understanding of career success. In what follows, we discuss the contextual mechanisms through which shared career success schemas are shaped.

\section{THE CONTEXTUAL EMBEDDEDNESS OF CAREER SUCCESS SCHEMAS}

Weber and Glynn's (2006) seminal paper on the role of institutional context in explaining cognition identifies three contextual mechanisms linking institutions to sensemaking: constraining, priming, and editing. Firstly, characteristics of institutions can constrain the availability (i.e., the existence of knowledge in memory), accessibility (i.e., the salience of the knowledge to a person), and activation (i.e., the putting into action of knowledge to guide judgment) of schemas people form in a given institutional context (Gelfand \& Brett, 2004). For example, a Finnish study among miners found that the term career success had very little meaning to them and that, instead, they tended to construe their understanding of career around the notion of sisu-i.e., "a Finnish word that roughly translates to inner determination and has been likened to qualities such as perseverance, determination, courage, and guts" (Lucas \& Buzzanell, 2004, p. 280). The authors argued that the societal lack of appropriate career success meanings applicable and recognizable to bluecollar workers constrains this group's cognitive representations of career success. In other 
words, the institution of occupation can be understood to constrain career success schema complexity (in the specific case of this study, among Finnish miners). Other institutional factors that can be expected to constrain career success schema complexity include a low level of economic development (Van de Vliert and Janssen, 2002) and collectivist cultural norms (Hofstede, 2001; House, Hanges, Javidan, Dorfman, \& Gupta, 2004). The former represents an objective constraint in the variety of available career opportunities (Oswald, 1997), while the latter operates through the link between collectivism and the tendency towards holistic, relational schemas (Nisbett \& Miyamoto, 2005).

Second, by prescribing appropriate identities, roles and frames for its citizens, institutions influence the formation of shared schemas through what Weber and Glynn (2006) call the 'priming' mechanism underlying collective sensemaking. Language, ideology, and discourse - typically disseminated through the mass media - play an important role. An example of a career success-related ideology with clear institutional roots is the American Dream. Through movies, aspirational self-made man stories, and self-help books this ideology primes a highly specific view of career success, while reinforcing the capitalist meritocratic socio-polictical system underlying it (Putnam, 2016). A largely opposite career ideology is propagated in socialist or communist institutional contexts (Lucas, Liu, \& Buzzanell, 2006). Cultural norms such as individualism and masculinity are part of the discourse reinforcing the capitalist ideology (Hofstede, 2001; House et al., 2004) and can thus be expected to exert an influence on career success schemas both separately and interactively (Claes \& Ruiz-Quintanilla, 1998). For example, in a masculine society people on average tend to be materialistic rather than idealistic. Materialism, in turn, has been found to encourage thinking in narrower categories, while idealism is associated with thinking in broader categories (Ogden \& Cheng, 2011). 
Third, both through pre-and post-employment socialization mechanisms (Rousseau, 2001) - i.e., social norms taught and reinforced through accumulated education and labor market experiences - career success schemas can be expected to be edited over time (Weber \& Glynn, 2006). All societies are characterized by conformity pressures, as adherence to social norms holds social groups together (Scott, 2004). The stronger a social norm- -for instance, as expressed through educational system standardization or rigid labor market regulations - the more likely it is to lead to high schema convergence (Tomlinson et al., 2018). In contrast, less regulated institutional settings are likely to facilitate less career success schema convergence as they allow for more idiosyncracies in the enactment of careers (Scherer, 2004). Similarly, cultural norms affect sensemaking about career success and thus the convergence of career success schemas. Specifically, individuals in collectivist societies are more likely than those in individualist societies to collectively edit the meaning of career success, and members of low power distance cultures (as opposed to high power distance cultures) are more likely to engage in proactive discussion about career success with higher-status individuals (Hofstede, 2001).

Although we offer some suggestions above as to how specific institutional factorssuch as economic development, educational systems, labor market regulations, and cultural norms such as collectivism, power distance, and masculinity—might affect career success schema complexity and convergence at the country level, it is important to understand that in the present paper we adopt an inductive, configurational approach to studying the relationships between institutional factors and career success schemas. The reason for this is that institutional factors — especially when doing studies at the country-comparative level— are best studied in bundles (Johns, 2006). To this end, we adopted a configurational approach building on the literature on qualitative comparative analysis (QCA; Ragin, 1994; Fiss, 2007). QCA allows for exploration of configurations of theoretically meaningful conditions 
and builds on a logic of conjunction, equifinality, and asymmetry (see Fiss, 2007; Greckhamer, 2016). For this study, this means that particular institutional factors may not affect career success schema complexity or convergence separately, but rather in conjunction with other factors. As a result, both career success schema complexity and convergence can be predicted by different configurations of institutional factors, forming qualitatively different, but equifinal prediction paths to the same outcome (e.g., high complexity). Finally, the configurations of institutional factors causing the presence of complexity or convergence will not necessarily be inverse to the configurations leading to their absence, which means that competing prediction paths are characterized by asymmetry (Fiss, 2007). These features of the configurational logic are essential for understanding and interpreting the results of our study as well as the inductive logic we use in developing propositions and directions for future research in the Discussion section.

\section{METHODS}

We adopted a sequential, country-comparative research design featuring a combination of cognitive mapping (Borgatti \& Halgin, 2011; Carley \& Palmquist, 1992) and QCA (Ragin, 1994; Fiss, 2007). We collected primary data for cognitive mapping and combined it with publically available, secondary data to perform the QCA. Our sample was stratified to ensure heterogeneity both at the between- and within-country level. At the between-country level, we sampled countries to represent Schwartz's (2006) cultural regions. Our final sample included Belgium, Brazil, China, France, Greece, India, Italy, Nigeria, Norway, South Korea, Slovenia, Turkey, and the US. The within-country sampling strategy aimed for heterogeneity specifically in terms of respondent occupations. It was important to account for occupations as they exert institutional influences, as the earlier example of Finnish miners suggested (see Lucas \& Buzzanell, 2004). 
The sampling plan was identical for all thirteen countries. Each participating country was instructed to sample 28 employed individuals (a common saturation point for card sort cognitive mapping studies) with at least five years of work experience, balanced in terms of gender, and representing seven different occupational strata from the Campbell (1995) interest typology (influencing [e.g., Advertising Account Executive], organizing [Accountant], helping [Nurse], creating [Writer], analyzing [Engineer], producing [Electrician], and adventuring [Police Officer]; each stratum is illustrated by a sample occupation). Within each occupational stratum, four representative occupations were sampled per country. For example, for Slovenia the adventuring stratum was represented by a criminal investigator, a fitness instructor, an expedition leader, and a firefighter.

Participants were recruited by local representatives of the global research project in line with the sampling plan. These local representatives also administered the cognitive mapping task and were available for assistance to respondents. Altogether, our sample included 364 individuals: $47 \%$ women, on average 40.7 years old $(S D=9.6)$, with around 16.4 years of work experience $(S D=9.6)$. Of our sample, $54 \%$ were white-collar workers; most respondents (43\%) held a bachelor degree or equivalent.

\section{Cognitive Mapping Procedure}

We used cognitive mapping to analyze career success schemas held by individual respondents and to derive country-level scores of career success schema complexity and convergence. Data on individual career success schemas were collected using an online card sort task. Card sorting is a qualitative technique where respondents are asked to logically organize a set of cards; in our case, each card featured a career success meaning (Daniels, De Chernatony, \& Johnson, 1995; Dries, Pepermans, \& Carlier, 2008). Specifically, respondents were asked to group 63 career success meanings into clusters personally meaningful to them. These 63 meanings of career success (for example: "Career success is... contributing to the 
development of others"; see Supplement for the complete list) were based on an earlier phase of the project, consisting of intensive semi-structured interviews $(N=226)$ about what career success meant to people in 11 countries (see Briscoe, Hall, \& Mayrhofer, 2011; Shen et al., 2015).

In the card sort task, respondents visually dragged and dropped the 63 career success meanings into clusters and then named the resulting clusters. We aggregated these individual sortings into country-level schemas by adopting the co-occurrence logic (see Supplement for more detail). The resultant, shared (i.e., country-level) career success schemas took the form of cognitive maps (see Supplement for some prototypical examples), in which nodes represent career success meanings, and the links among them shared views of country members about which pairs of career success meanings belong to the same cluster (De Nooy, Mrvar \& Bategelj, 2011; Borgatti \& Halgin, 2011). As a next step, we derived the complexity and convergence scores for each country. These scores represented the basis for developing our two-by-two career success schema taxonomy at the country level.

Career success schema complexity. Career success schema complexity was operationalized as the opposite of the total connectivity of career success meanings across a country's respondents (see Zerubavel, 1996). Total connectivity counts the aggregate number of times any pair of career success meanings was grouped together by individual respondents. To illustrate, if all country respondents split each of the 63 career success meanings into 63 separate clusters, that would generate the highest possible complexity of career success schemas in a country (i.e., extreme splitting). Alternatively, if all country respondents lumped all career success meanings together into one single cluster, that would generate the lowest possible complexity (i.e., extreme lumping).

Career success schema convergence. Career success schema convergence was operationalized as the proportion of connectivity among career success meanings that was 
shared by the majority of country respondents. It was calculated as the ratio between shared connectivity (see Jonker, et al., 2011) — the aggregate number of times any pair of career success meanings was grouped together by majority or respondets in a country — and total connectivity (see above).

\section{Qualitative Comparative Analysis Procedure}

We performed QCA to determine which configurations of contextual factors relate to the presence and absence of career success schema complexity and convergence at the country level along with which configurations relate to particular archetypes in our taxonomy. The first step in QCA is defining sets representing outcomes (i.e., countries with presence and absence of high career success schema complexity and convergence) and causal conditions (i.e., countries with high levels of the relevant contextual factors). Sets were defined though calibration, where theoretical and empirical knowledge was used to set thresholds for a crisp-set QCA (i.e., a type of QCA that operates with binary variables; see Ragin, 1994; Fiss, 2007). Outcomes and conditions were dichotomized leading to subsets of cases (here, countries) above a threshold, or fulfilling a given condition for being defined as set members (1), and below the threshold (or not fulfilling a given condition) as nonmembers (0). Country membership for the outcomes (i.e., complexity and convergence) came from our comparative cognitive mapping study, whereas country membership for the institutional conditions was based on publicly available secondary data for the year of data collection, or the closest available year to that year. Respective country memberships are found in Table 1.

General country development. General country development was measured by UNESCO's Human Development Index (HDI). The HDI is a robust index encompassing life expectancy at birth, expected years of schooling, mean years of schooling for adults aged 25 , and standard of living (gross national income per capita). Data for all countries in our sample 
were available. Using the UNESCO's official threshold, we differentiated between countries with a very high HDI (above 0.8 ) and countries below this threshold.

Labor market flexibility. Labor market flexibility was measured using the strictness of employment protection index of the Organization for Economic Cooperation and Development (OECD). The global average for this indicator (2.084) was used as a threshold for determining country membership. Data were available for all countries except for Nigeria. Therefore, we imputed membership for Nigeria based on a related index of labor freedom published by the The Heritage Foundation. Nigeria was classified among the countries with a less strict employment protection legislation.

Standardization of the educational system. Standardization of the educational system was measured using factor scores of indicators of input standardization of educational systems (i.e., the extent to which schools are autonomous in choosing textbooks, determining course content, and courses offerings; Bol \& Van de Werfhorst, 2013). The data for this measure were gathered as a part of the OECD's Programme for International Student Assessment (PISA). The threshold value for the factor was set at 1.00 (the mean factor value was 0.0 and the standard deviation was 1.00 ), which means that all countries that were one standard deviation above the international mean were considered highly standardized. Scores for China, India and Nigeria were imputed based on publically available descriptions of their educational systems and by means of comparison to countries with available data. Consequently, China and Nigeria (but not India) were classified as countries with highly standardized educational systems.

Cultural dimensions. Values for three cultural dimensions (i.e., individualism, masculinity, and power distance) were based on publicly available scores for each country. We decided to use Hofstede's (2001) cultural indicators scores due to parsimony of the cultural dimensions, availability of data for all countries in the sample, and predetermined 
global thresholds. In line with these tresholds country memberships were set based on the critical value of 50 (on a 100-point scale).

- Insert Table 1 about here-

QCA builds on the identified country memberships for both outcomes and institutional factors, and employs Boolean algebra to determine how different configurations of contextual factors lead to presence and absence of each combination of outcomes. The configurations are compared and logically simplified (Hollingsworth, Hanneman, Hage \& Ragin, 1996) to determine which of them lead to presence and which to absence of the outcomes. To reiterate, the focus of QCA is not on testing the significance of effects of individual factors on outcomes, but rather on identifying configurations of factors that lead to the presence and/or absence of outcomes.

\section{RESULTS}

\section{Cognitive Mapping}

The cognitive mapping procedure provided inputs for calculating the complexity and convergence scores across countries. Based on the distributions of theses scores, we determined a threshold value for both measures based on scree-plot discontinuity (Turner, 1998). Based on the units of measure for this dimension, the threshold for complexity was set to 75,000; as a result, Belgium, the US, Italy, France, Norway, Slovenia, and Greece were classified as members of the high-complexity cluster (see Table 2). Similarly, based on the units of measure for schema convergence (ratio), the threshold value was set to 0.15 . As a result, Italy, Slovenia, South Korea, Greece, Belgium, the US and Norway were classified as members of the high-convergence cluster (see Table 2).

—Insert Table 2 about here-

Having established the countries characterized as high vs. low complexity and high vs. low convergence, in the next step we developed a two-by-two taxonomy. Here we 
classified country-level career success schemas into four archetypes which we labeled as: modular (high complexity, high convergence; prototypical example: Belgium), holistic (low complexity, high convergence; prototypical example: South Korea), weakly modular (high complexity, low convergence; prototypical example: France), and diffused (low complexity, low convergence; prototypical example: China).

\section{Qualitative Comparative Analysis}

Based on our selected set of contextual factors as described in the Methods section, we performed QCA analyses using the entry data depicted in Table 1. Using the fsQCA software (Ragin, 1994) we assessed specific sets of configurations of institutional factors leading to: (1) presence of schema complexity, (2) absence of schema complexity, (3) presence of schema convergence, and (4) absence of schema convergence (cf. Greckhamer, Misangyi, Elms and Lacey, 2008). The results of the intermediate solutions (see Ragin, Strand and Rubinson, 2008, p.74)—where logical simplification is combined with theoretical assumptions to derive configurations_-are presented in Tables 3 and 4.

As seen in Table 3, for high career success schema complexity, three configurations emerged. The two most dominant configurations were $\mathrm{c} 1.1$, which was associated with the simultaneous presence of high general country development, low standardization of the educational system, high individualism, and high masculinity; and c1.2, which featured the simultaneous presence of high general country development, low labor market flexibility, low standardization of the educational system, and high individualism. The remaning path (c1.3) included high general country development, low labor market flexibility, high standardization of the educational system, and high power distance. All three configurations leading to high levels of career success schema complexity included the presence of high general country development, indicating that this was a necessary condition for career success schema complexity. 
Alternatively, for low career success schema complexity, two configurations were found (see Table 3). The highly dominant path (c2.1) was associated with the simultaneous presence of low general country development, along with low individualism and high power distance. The remaining configuration (c2.2) featured low labor market flexibility, low standardization of the educational systesm, low individualism, low masculinity, and high power distance. It also exhibited very limited coverage of the participating countries. Both configurations (c2.1, c2.2) included high power distance and low individualism, indicating that these two factors (and their combination) represented necessary conditions for the absence of career success schema complexity.

—Insert Table 3 about here-

As can be seen in Table 4, for high career success schema convergence, the dominant path (c3.1) was associated with the simultaneous presence of high general country development and high masculinity. The next configuration in terms of coverage (c3.2) featured high general country development, low labor market flexibility and low individualism. The remaining configuration with lowest country coverage included high general country development, low labor market flexibility, and low power distance. All three configurations $(\mathrm{c} 3.1, \mathrm{c} 3.2, \mathrm{c} 3.3)$ included high general country development, indicating that this was a necessary condition for career success schema convergence.

Alternatively, for low career success schema convergence, the highly dominant configuration in terms of country coverage (c4.1) was associated with the simultaneous presence of low general country development and high power distance. The second configuration (c4.2) exhibited very limited country coverage and featured low standardization of the educational system combined with high individualism, low masculinity, and high power distance. Both configurations (c4.1, c4.2) included high power distance, indicating that this was a necessary condition for the absence of career success schema convergence. 
- Insert Table 4 about here-

Having established the configurations that predicted career success schema complexity and convergence, we further leveraged Boolean logic to derive configurations leading to the four archetypes of career success schemas at the country level (see Table 5). For example, contextual features leading to the high-complexity, high-convergence archetype were derived by logically combining underlying configurations for complexity (c1.1, c1.2, c1.3) and for convergence (c3.1, c3.2, c3.3). The results reveal that the holistic and weakly modular archetypes had weak representation in participating countries (only one country representaitive each), while modular and diffused types had stonger representation (both featured multiple representative countries). The solution for the modular archetype was by far the most complex: it featured four configurations. Although all four configurations included high general country development - a necessary condition for this archetype - the exact combination of institutional factors leading to the modular archetype was quite diverse. This finding underscores the equifinality principle and demonstrates that the configurational approach is highly applicable to the topic of career success schemas.

—Insert Table 5 about here-

\section{DISCUSSION}

The present study is the first to conceptualize and methodologically demonstrate how the meaning of career success is not only individually, but also collectively constructed. It is generally recognized that the present-day careers literature is overly focused on individual agency (Cohen, Duberley, \& Mallon, 2004) and that there is a lack of understanding of how macro-level context variables influence careers (Mayrhofer, Meyer, \& Steyres, 2007). In addition, research on career systems in MNEs has concluded that an ethnocentric approachin which a career system is designed at headquarters and 'exported' to all subsidiaries — often fails, and that ignoring institutional and cultural differences between countries can lead to 
conflict situations (Boussebaa \& Morgan, 2008). Responding to calls for a better understanding of career success across country contexts (Kraimer et al., 2011; Mayrhofer et al., 2004), in the present paper we propose that such an understanding must start with the fundamental building blocks of careers - i.e., the cognitions underlying them, largely subconsciously shaped through socialization and experience (Rousseau, 2001; Weber \& Glynn, 2006). Only when we understand how people from different parts of the world 'see' careers, can we start designing career management systems that make sense cross-nationally (Evans et al., 2002).

Thus, we introduced the concept of career success schemas and examined country differences in their structural characteristics. In particular-adopting schema complexity and convergence as primary dimensions - we proposed a two-by-two taxonomy that can be used to classify career success schemas at the country level, and then derived configurations of relevant contextual factors leading to high (vs. low) complexity and convergence of career success schemas. Our results showed that there are important differences in the structural characteristics of career success schemas across a globally diverse sample. Here, we review key study results and offer some specific propositions about emergence of country-level career success schemas.

Whereas in some countries (e.g., South Korea, Brazil, and China) people had a tendency to lump many career success meanings together, in other countries (e.g., Belgium, Italy, and the United States) people clustered career success meanings in more complex ways (see also Figures S1-S4 in the Supplement). In addition, the level of convergence of individuals' career success schemas varied widely across countries. Norway, for example, showed the strongest convergence and India the lowest.

Our resulting taxonomy furthermore demonstrated that the modular career success schema-which represents the dominant, multidimensional view on subjective career success 
in the careers literature today (e.g., Shockley et al., 2016) — is only one of four archetypes of career success schemas, the others being holistic, diffused, and weakly modular (see Table 5). An additional observation is that the countries where most research on the multidimensional nature of career success has been done typically belong to this cluster. We must thus conclude first, that a variety of career success schemas is found across countries and second, that comparative HRM researchers and practitioners in MNEs need to be mindful of the dominance of the modular perspective on career success.

This is not only theoretically important, but likely also influences the practice of organizational career management in MNEs, as we discuss later. We propose that a simultaneous presence of high country-level schema complexity and convergence is an important condition to meaningful interpretation of multidimensional models of career success on the one hand, and meaningful comparisons between countries on the other. Schema convergence, in particular, is important for interpreting career success schemas in a country as 'shared'. When convergence is low, it becomes difficult to interpret a country's understanding of career success at the collective level (Jonker et al., 2010; Schaller \& Crandall, 2003).

Country differences in schema characteristics were also found to be meaningfully related to various configurations of contextual factors, demonstrating the contextual embeddedness of career success schemas. Two configurations stood out in particular and prompted us to develop the following propositions:

Proposition 1: Low career schema complexity is typically found in institutional settings characterized by a combination of low individualism and high power distance.

Proposition 2: High career schema convergence is typically found in institutional settings characterized by high general country development. 
High general country development—as measured by UNESCO's Human Development Index (HDI) - also emerged as a necessary condition for the modular career success schema, where both high complexity and convergence have to be present at the same time:

Proposition 3a: High general country development is a necessary condition for development of the modular country-level career success schema.

In highly developed countries, there will likely be fewer constraints in terms of the availability, accessibility, and activation of different career success meanings, and thus higher career success schema complexity (Gelfand \& Brett, 2004). Put simply, this means that a wider range of career success meanings will be available to a wider range of people in such countries (Lucas et al., 2006). At the same time, these countries are also more likely to achieve schema convergence, possibly because their educational systems are more standardized, which stimulates shared editing —-i.e., a strongly normative socialization —of people's career success meanings as they mature into working-age adults (Weber \& Glynn, 2006). Our findings, however, do not automatically imply that all highly developed countries will have a modular career success schema:

Proposition 3b: High general country development is a necessary, but insufficient condition for development of the modular country-level career success schema.

To back this proposition, note that South Korea and France were not members of the modular archetype in spite of their high levels of general country development. Our study thus confirms that although particular institutional factors might play a pivotal role in understanding country differences in career success schemas, a configurational approach is 
more appropriate to fully grasp how bundles of institutional factors relate to career success schema complexity and convergence and their interplay (cf. Johns, 2006).

\section{Implications for Research}

First, our results demonstrate and challenge the dominance of modular career success schemas in careers research, in particular the implicit assumption that subjective career success is a multidimensional construct consisting of a relatively high number of distinct independent factors. Our data imply that a modular career success schema is only applicable in certain countries. It therefore seems relevant for future research to explore how subjective career success models and measures can be developed that are applicable in countries with non-modular career success schemas. One solution might be to determine the dimensionality of any such models by relying on cognitive mapping techniques rather than traditional factor analysis approaches (see Briscoe et al., 2014). Future research would do well to look at relationships between subjective career success meanings (Borgatti \& Halgin, 2011), rather than following a rigid factor structure logic which entails 'separating' meanings from each other. Such a procedure may allow researchers to find robust clusters of career success meanings that are shared across countries, versus clusters that are more country-specific (Mayrhofer et al., 2016).

Second, our study shows that career success schemas are a useful construct for better understanding the role of context in comparative research on career systems in MNEs. The careers literature has tended to strongly emphasized agency and self-directedness - an approach that is increasingly criticized for being too one-sided and concealing the many structural factors that also play a role in how careers develop (Cohen et al., 2004). In the present study, we developed a theoretical framing fusing institutional theory with collective sensemaking (Weber \& Glynn, 2006) to foster the identification of mechanisms through which institutional contexts affect the development of shared career success schemas. Our 
study thus offers an important foundation for theorizing how subjective career success is societally constructed. Future research should therefore take into account the collectively shared meanings of career success and further examine how these meanings are formed compared to other institutional contexts (Hirschfeld \& Gelman, 1994).

Third — and in line with the longstanding agency-structure debate in careers research (Cohen et al., 2004) - another intriguing direction for further research may be to explore how country-level career success schemas affect individuals' career-related sensemaking, decisions and behaviors, as well as the effects of a (mis)match between an individuals' schemas and collective schemas. We might expect that in countries with high convergence, more people would have an understanding of career success that matches the dominant career success schema. However, in such a context, having a mismatched individual career schema might be more complicated and potentially more harmful. Indeed, following norm theory (Kahneman \& Miller, 1986), stronger schema convergence in a given context implies stronger norms about what is seen as a successful career and what is not. The stronger the norm, the more likely that deviations may be perceived as abnormal and induce negative emotional responses (Johns, 2006). Conversely, in contexts with lower schema convergence, the norms may be weaker, leaving more room for agentic career behavior. Overall, we believe cross-cultural research into individual and collective career success schemas could generate new insights into the agency-structure debate.

Finally, an important avenue for further research is to examine the specific meanings of career success both within and between countries, as well as the country-specific interrelationships between meanings. Understanding which specific meanings are related to each other in a certain context may be particularly useful for HR practitioners in MNEs, to attune their career management systems to their subsidiary countries' specific patterns. Such an approach may help MNEs design career management systems that either apply globally or 
alternatively, are 'glocalized' in acknowledging cultural and institutional differences in cognitions of career success (Rosenzweig, 2006).

Further research may thus want to shift the emphasis from structural characteristics of careers success schemas to their content, as the meaning of a career facet to an individual depends on its relationships to other facets in the cognitive network (Rousseau, 2001). For instance, two individuals may indicate that they both consider salary highly important in their personal understanding of career success. However, upon examination it turns out that for one of them pay is associated with status and recognition, while for the other, it is associated with family, duty, and financial security. While the former sees career success as an individual achievement, the latter sees it more as a relational construct, in that the money is a means to providing for his or her family or community. In other words, although the subscale (i.e., factor-level) score for financial achievement as a measure of success may be the same for both, financial achievement itself holds a fundamentally different meaning to each of them (Rousseau, 2001). In conclusion, a better understanding of the 'content' of countrylevel career success schemas may provide useful insights for comparative research on career systems in MNEs, especially in countries with high convergence.

\section{Limitations}

As in any study, limitations must be acknowledged. First, due to the qualitative and inductive nature of the research only a limited number of contextual factors (out of a very large number of potential factors) were selected as likely conditions to career schema complexity and convergence. Our inductive approach does not preclude identification of new configurations leading to the outcomes in future studies, which is consistent with the equifinality principle that is one of the cornerstones of the QCA (see Fiss, 2007; Ragin 1994). Second, we utilized country-level data from sources that were consistent with our theoretical framing and available for the countries under study. For example, in deciding between 
GLOBE's and Hofstede's cultural dimensions we decided on the latter because of its theoretical relevance to career success (e.g., Ramaswami, Huang, \& Dreher, 2014), extensive country coverage (all countries in our sample) and its parsimony - thus we could cover the relevant cultural norms corresponding to our theoretical mechanisms with fewer dimensions in the QCA. Although Hofstede's cultural framework has been subject to critique, it has continued to provide valuable cross-cultural research insights (Taras, Kirkman, \& Steel, 2010). Finally, although the number of individual respondents (28 per country) and coverage of countries (13 countries from a wide variety of regions; Schwartz, 2006) was more than sufficient for the purpose of this paper, future studies should try to empirically test the proposed taxonomy on a larger sample of countries using a deductive approach or a largerscale QCA.

\section{Implications for Practice}

Our findings imply that MNEs should evaluate and rethink the appropriateness of their career management systems across different institutional settings, based on the foundational career success schemas upon which these systems are likely based. We show important country-level variations in the complexity and convergence of career success schemas, which has important implications for policy makers, HR professionals and MNEs in particular, as not all countries form career schemas in the 'traditional', modular manner. Put another way, an ethnocentric approach to career management is likely only suitable for MNEs with subsidiaries belonging to the same career success schema archetype (cf. Table 5).

In countries that have more modular career success schemas, traditional career management systems and HR practices are probably well-suited as they likely focus on a variety of well-understood meanings of career success (for instance, the provision of upward career paths tied to the meaning of success as pay and status; family-friendly work arrangements attuned to the career success meaning of work-life balance). In countries where 
there is little convergence of career success schemas, however, it may be difficult and likely ineffective to impose the same career management practices upon everyone (for instance, a person may aspire a higher salary, but if that person's salary is associated with better worklife balance, being promoted would not be the ideal HR practice for him or her). Even more problematic, in countries characterized by low complexity, the use of (Western) HR practices singling out specific career success meanings (where, for example, bonuses and salaries are handled separate from learning and development) may hinder prediction and measurement of the impact of individual HR interventions on employee morale (Newman \& Nollen, 1996). In such countries, organizational career management and HR practices may need to be more holistic, since in those settings, meanings of career success are interconnected and hard to separate. As MNEs and other firms from westernized and developed countries continue to seek a higher percentage of revenue from operations in emerging and growth-leading economies (i.e., the so-called EAGLEs) (Brewster and Mayrhofer, 2012)—which, according to our findings, can be expected to be characterized by diffuse career success schemas - these warnings may be especially salient. 


\section{REFERENCES}

Al Ariss, A. (2010). Modes of engagement: migration, self-initiated expatriation, and career development. Career Development International, 15(4), 338-358.

Aryee, S., Chay, Y.W., \& Tan, H.H. (1994). An examination of the antecedents of subjective career success among a managerial sample in Singapore. Human Relations, 47(5), 487-509.

Baruch, Y., \& Peiperl, M. (2000). Career management practices: An empirical survey and implications. Human Resource Management, 39(4), 347-366.

Baruch, Y., \& Vardi, Y. (2016). A fresh look at the dark side of contemporary careers: Toward a realistic discourse. British Journal of Management, 27(2), 355-372.

Blustein, D.L., Palladino-Schultheiss, D.E., \& Flum, H. (2004). Toward a relational perspective of the psychology of careers and working: A social constructionist analysis. Journal of Vocational Behavior, 64(3), 423-440.

Bol, T. \& Van de Werfhorst, H. G. (2013). The measurement of tracking, vocational orientation, and standardization of educational systems: A comparative approach. Gini Discussion Paper 81.

Borgatti, S. P. \& Halgin, D. S. (2011). Mapping culture: Freelists, pilesorting, triads and consensus analysis. In J. Schensul and M. LeCompte (Eds.), The ethnographer's toolkit, vol. 3. Walnut Creek: Altamira Press.

Boussebaa, M., \& Morgan, G. (2008). Managing talent across national borders: the challenges faced by an international retail group. Critical Perspectives on International Business, 4(1), 25-41.

Briscoe, J.P., Hall, D.T., \& Mayrhofer, W. (Eds.) (2011). Careers around the world: Individual and contextual perspectives. New York: Routledge. 
Briscoe, J.P., Kaše, R., Dries, N., Dysvik, A., Unite, J., Övgü Çakmak-Otluoğlu, K., ... \& Verbruggen, M. (2014). A cross-culturally generated measure of perceived career success: Results of a three-stage study. In J. Humphreys (Eds). 2014 Best Paper Proceedings, 74th Academy of Management Annual Meeting, Philadelphia, PA.

Caligiuri P., Lepak, D., \& Bonache, J. (2010). Managing the global workforce. West Sussex: Wiley.

Campbell, D. P. (1995). The Campbell Interest and Skill Survey (CISS): A product of ninety years of psychometric evolution. Journal of Career Assessment, 3(4), 391-410.

Carley, K., \& Palmquist, M. (1992). Extracting, representing, and analyzing mental models. Social Forces, 70(3), 601-636.

Claes, R., \& Ruiz-Quintanilla, S. A. (1998). Influences of early career experiences, occupational group, and national culture on proactive career behavior. Journal of Vocational Behavior, 52(3), 357-378.

Cohen, L., Duberley, J., \& Mallon, M. (2004). Social constructionism in the study of career: Accessing the parts that other approaches cannot reach. Journal of Vocational Behavior, 64(3), 407-422.

Conway III, L. G., Schaller, M., Tweed, R. G., \& Hallett, D. (2001). The complexity of thinking across cultures: Interactions between culture and situational context. Social Cognition, 19(3: Special issue), 228-250.

Daniels, K., De Chernatony, L., \& Johnson, G. (1995). Validating a method for mapping managers' mental models of competitive industry structures. Human Relations, 48(9), 975-991.

De Nooy, W., Mrvar, A., \& Batagelj, V. (2011). Exploratory social network analysis with Pajek (Vol. 27). Cambridge University Press. 
Dries, N., Pepermans, R., \& Carlier, O. (2008). Career success: Constructing a multidimensional model. Journal of Vocational Behavior, 73(2), 254-267.

Eby, L. T., Durley, J. R., Evans, S. C., \& Ragins, B. R. (2006). The relationship between short-term mentoring benefits and long-term mentor outcomes. Journal of Vocational Behavior, 69(3), 424-444.

Engelhardt, H. (2011). Late careers in Europe: effects of individual and institutional factors. European Sociological Review, 28(4), 550-563.

Evans, P., Pucik, V., \& Barsoux, J. L. (2002). The global challenge. McGraw-Hill Publishing Company.

Fassin, Y., Werner, A., Van Rossem, A., Signori, S., Garriga, E., von Weltzien Hoivik, H., \& Schlierer, H. J. (2015). CSR and related terms in SME owner-managers' mental models in six European countries: National context matters. Journal of Business Ethics, 128(2), 433-456.

Fayer, S., Lacey, A., \& Watson, A. (2017). STEM Occupations: Past, Present and Future. U.S. Bureau of Labor Statistics, Spotlight on Statistics, January, 2017.

Fiss, P. C. (2007). A set-theoretic approach to organizational configurations. Academy of Management Review, 32(4), 1180-1198.

Furlow, C. A. (2003). Comparing indicators of knowledge within and between cultural domains. Field Methods, 15(1), 51-62.

Gabriel, Y., Gray, D. E., \& Goregaokar, H. (2010). Temporary derailment or the end of the line? Managers coping with unemployment at 50. Organization Studies, 31(12), 16871712.

Gelfand, M. J., \& Brett, J. M. (2004). The handbook of negotiation and culture. Stanford University Press. 
Greckhamer, T. (2016). CEO compensation in relation to worker compensation across countries: the configurational impact of country-level institutions. Strategic Management Journal, 37, 793-815.

Greckhamer, T., Misangyi, V. F., Elms, H., \& Lacey, R. (2008). Using QCA in strategic management research: An examination of combinations of industry, corporate, and business unit effects. Organizational Research Methods, 11(4), 695-726.

Gunz, H. P., \& Heslin, P. A. (2005). Reconceptualizing career success. Journal of Organizational Behavior, 26(2), 105-111.

Gunz, H., Evans, M., \& Jalland, M. (2000). Career boundaries in a 'boundaryless' world. Career frontiers: New conceptions of working lives, 24-53.

Hall, D. T., \& Chandler, D. E. (2005). Psychological success: When the career is a calling. Journal of Organizational Behavior, 26(2), 155-176.

Hirschfeld, L. A., \& Gelman, S. A. (1994). Mapping the mind: Domain specificity in cognition and culture. Cambridge, MA: Cambridge University Press.

Hofstede, G. (2001). Culture's consequences: Comparing values, behaviors, institutions, and organizations across nations. Thousand Oaks, CA: Sage.

Hollingsworth, R., Hanneman, R., Hage, J., \&Ragin, C. (1996). The effect of human capital and state intervention on the performance of medical systems. Social Forces, 75(2), $459-484$.

House, R. J., Hanges, P. J., Javidan, M., Dorfman, P. W., \& Gupta, V. (2004). Leadership, culture and organizations: The GLOBE study of 62 societies. Thousand Oaks, CA: Sage Publications Inc.

Johns, G. (2006). The essential impact of context on organizational behavior. Academy of Management Review, 31(2), 386-408. 
Jones, N. A., Ross, H., Lynam, T., Perez, P. \& Leitch, A. (2011). Mental models: An interdisciplinary synthesis of theory and methods. Ecology and Society, 16(1), 46.

Jonker, C. M., Van Riemsdijk, M. B., \& Vermeulen, B. (2011). Shared mental models. In: Coordination, organizations, institutions, and norms in agent systems VI (pp. 132-151). Springer Berlin Heidelberg.

Judge, T.A., Cable, D.M., Boudreau, J.W., \& Bretz, R.D. (1995). An empirical investigation of the predictors of executive career success. Personnel Psychology, 48(3), 485-519.

Leung, S. A. (2008). The big five career theories. In International handbook of career guidance (pp. 115-132). Springer, Dordrecht.

Liu, L. A., Friedman, R., Barry, B., Gelfand, M. J., \& Zhang, Z. (2012). How to build consensus in negotiation? A dynamic theory of mental models within and across cultures. Paper presented at the $1^{\text {st }}$ Inernational Conference on Cross-Cultural Decision Making. Miami, Florida.

Lucas, K., \& Buzzanell, P. M. (2004). Blue-collar work, career, and success: Occupational narratives of Sisu. Journal of Applied Communication Research, 32(4), 273-292.

Lucas, K., Liu, M. \& Buzzanell, P.M. (2006). No limits careers: A critical examination of career discourse in the US and China. In Orbe, M., Allen, B.J. and Flores, L.A. (Eds), International and Intercultural Communication Annual Vol. 28. Sage, Thousand Oaks, CA, pp. 217-242.

Mayrhofer, W., Briscoe, J. P., Hall, D. T. T., Dickmann, M., Dries, N., Dysvik, A., ... \& Unite, J. (2016). Career success across the globe. Organizational Dynamics, 3(45), 197205.

Mayrhofer, W., Meyer, M., Iellatchitch, A., \& Schiffinger, M. (2004). Careers and human resource management — a European perspective. Human Resource Management Review, 14(4), 473-498. 
McSweeney, B. (2002). Hofstede's model of national cultural differences and their consequences: A triumph of faith-a failure of analysis. Human Relations, 55(1), 89-118.

Moussavi, F., and Evans, D. A. (1993). Emergence of organizational attributions: The role of a shared cognitive schema. Journal of Management, 19(1), 79-95.

Ng, T. W., Eby, L. T., Sorensen, K. L., \& Feldman, D. C. (2005). Predictors of objective and subjective career success: A meta-analysis. Personnel Psychology, 58(2), 367-408.

Nisbett, R. E., \& Miyamoto, Y. (2005). The influence of culture: Holistic versus analytic perception. Trends in Cognitive Sciences, 9(10), 467-473.

Nisbett, R. E., Peng, K., Choi, I., \& Norenzayan, A. (2001). Culture and systems of thought: Holistic versus analytic cognition. Psychological Review, 108(2), 291-310.

Ogden, H., \& Cheng, S. (2011). Cultural dimensions and materialism: Comparing Canada and China. Asia Pacific Journal of Marketing and Logistics, 23(4), 431-447.

Oswald, A.J (1997). Happiness and economic performance. The Economic Journal, 107(445), 1815-1831.

Palmer, T. B., \& Pickett, G. M. (1999). The role of mental models in control theory: Understanding cognitive factors influencing the behaviors of salespeople. Journal of Marketing Theory and Practice, 7(1), 17-29.

Putnam, R. D. (2016). Our kids: The American dream in crisis. New York, NY: Simon and Schuster.

Ragin, C. (1994). Introduction to Qualitative Comparative Analysis. In Janoski and Hicks (Eds.), The comparative political economy of the welfare state (pp. 299-319). Cambridge, MA: Cambridge University Press.

Ragin, C. C., Strand, S., \& Rubinson, C. (2008). User's guide to Fuzzy-Set/ Qualitative Comparative Analysis. 
Ramaswami, A., Huang, J. C., \& Dreher, G. (2014). Interaction of gender, mentoring, and power distance on career attainment: A cross-cultural comparison. Human Relations, 67(2), 153-173.

Rosenzweig, P.M. (2006). The dual logics behind international human resource management: Pressures for global integration and local responsiveness. In G. K. Stahl \& I. Björkman (Eds.), Handbook of research in international human resource management: 36-48. Cheltenham, UK: Edward Elgar.

Rousseau, D. M. (2001). Schema, promise and mutuality: The building blocks of the psychological contract. Journal of Occupational and Organizational Psychology, 74(4), $511-541$

Scott, R. (2004). Institutional theory: contributing to a theoretical research program. In Smith, K.G. and Hitt, M.A. (Eds), Great minds in management: The process of theory development. Oxford University Press, New York, NY.

Schaller, M., \& Crandall, C. S. (Eds.). (2003). The psychological foundations of culture. Mahweh, NJ: Psychology Press.

Schwartz, S. H. (2006). A theory of cultural value orientations: Explication and applications. Comparative Sociology, 5(2), 137-182.

Seibert, S. E. (2006). Career success. In J. H. Greenhaus and G. A. Callanan (Eds.), Encyclopedia of career development. San Francisco, CA: Sage.

Shen, Y., Demel, B., Unite, J., Briscoe, J. P., Hall, D. T., Chudzikowski, K., ... \& Fei, Z. (2015). Career success across 11 countries: implications for international human resource management. International Journal of Human Resource Management, 26(13), 17531778. 
Shockley, K. M., Ureksoy, H., Rodopman, O. B., Poteat, L. F., \& Dullaghan, T. R. (2016). Development of a new scale to measure subjective career success: A mixed-methods study. Journal of Organizational Behavior, 37(1), 128-153.

Spicer, D. P. (1998). Linking mental models and cognitive maps as an aid to organisational learning. Career Development International, 3(3), 125-132.

Stumpf, S. A., Doh, J. P., \& Tymon, W. G. (2010). The strength of HR practices in India and their effects on employee career success, performance, and potential. Human Resource Management, 49(3), 353-375.

Taras, V., Kirkman, B. L., \& Steel, P. (2010). Examining the impact of Culture's consequences: A three-decade, multilevel, meta-analytic review of Hofstede's cultural value dimensions. Journal of Applied Psychology, 95(3), 405-439.

Tomlinson, J., Baird, M., Berg, P., \& Cooper, R. (2018). Flexible careers across the life course: Advancing theory, research and practice. Human Relations, 71(1), 4-22.

Turner, N. E. (1998). The effect of common variance and structure pattern on random data eigenvalues: Implications for the accuracy of parallel analysis. Educational and Psychological Measurement, 58(4), 541-568.

Van De Vliert, E. \& Janssen, O. (2002). Better-than performance motives as roots of satisfaction across more and less developed countries. Journal of Cross-Cultural Psychology, 33(4), 380-397.

Weber, K., \& Glynn, M. A. (2006). Making sense with institutions: Context, thought and action in Karl Weick's theory. Organization Studies, 27(11), 1639-1660.

Williamson, D. (2002). Forward from a critique of Hofstede's model of national culture. Human Relations, 55(11), 1373-1395. 
Winn, W., \& Snyder, D. (1996). Cognitive perspectives in psychology. Handbook of research for educational communications and technology: A project of the Association for Educational Communications and Technology, 79-112.

Zerubavel, E. (1996). Lumping and splitting: Notes on social classification. Sociological Forum, 11(3), 421-433. 
Table 1

Entry Data for Qualitative Comparative Analysis

\begin{tabular}{|c|c|c|c|c|c|c|c|c|}
\hline Country & $\begin{array}{c}\text { Career } \\
\text { Success } \\
\text { Schema } \\
\text { Complexity }\end{array}$ & $\begin{array}{c}\text { Career } \\
\text { Success } \\
\text { Schema } \\
\text { Convergence }\end{array}$ & $\begin{array}{c}\text { General } \\
\text { Country } \\
\text { Development }\end{array}$ & $\begin{array}{c}\text { Labor } \\
\text { Market } \\
\text { Flexibility }\end{array}$ & $\begin{array}{c}\text { Standardization } \\
\text { of Educational } \\
\text { System }\end{array}$ & $\begin{array}{c}\text { Power } \\
\text { Distance }\end{array}$ & Individualism & Masculinity \\
\hline Belgium & 1 & 1 & 1 & 1 & 0 & 1 & 1 & 1 \\
\hline Brazil & 0 & 0 & 0 & 1 & 0 & 1 & 0 & 0 \\
\hline China & 0 & 0 & 0 & 0 & 1 & 1 & 0 & 1 \\
\hline France & 1 & 0 & 1 & 0 & 0 & 1 & 1 & 0 \\
\hline Greece & 1 & 1 & 1 & 0 & 1 & 1 & 0 & 1 \\
\hline India & 0 & 0 & 0 & 0 & 0 & 1 & 0 & 1 \\
\hline Italy & 1 & 1 & 1 & 0 & 0 & 1 & 1 & 1 \\
\hline Nigeria & 0 & 0 & 0 & 1 & 1 & 1 & 0 & 1 \\
\hline Norway & 1 & 1 & 1 & 0 & 0 & 0 & 1 & 0 \\
\hline S. Korea & 0 & 1 & 1 & 0 & 0 & 1 & 0 & 0 \\
\hline Slovenia & 1 & 1 & 1 & 0 & 1 & 1 & 0 & 0 \\
\hline Turkey & 0 & 0 & 0 & 0 & 1 & 1 & 0 & 0 \\
\hline USA & 1 & 1 & 1 & 1 & 0 & 0 & 1 & 1 \\
\hline
\end{tabular}


EMBEDDEDNESS OF CAREER SUCCESS SCHEMAS

Table 2

Scores Derived from Cognitive Mapping for Setting Thresholds

\begin{tabular}{lccc}
\hline Country & Total Connectivity & Shared Connectivity & Convergence \\
\hline Belgium & 53,348 & 9,714 & 0.182 \\
Brazil & 78,184 & 9,620 & 0.123 \\
China & 80,376 & 9,306 & 0.116 \\
France & 63,866 & 8,642 & 0.135 \\
Greece & 71,072 & 12,906 & 0.182 \\
India & 75,952 & 7,832 & 0.103 \\
Italy & 63,602 & 10,092 & 0.159 \\
Nigeria & 78,616 & 8,990 & 0.114 \\
Norway & 67,816 & 17,142 & 0.253 \\
S. Korea & 81,582 & 14,326 & 0.176 \\
Slovenia & 69,822 & 11,258 & 0.161 \\
Turkey & 76,758 & 9,350 & 0.122 \\
USA & 58,418 & 11,816 & 0.202 \\
\hline
\end{tabular}

Note. Threshold value set at 75,000 for Total Connectivity, which is opposite of Complexity, and at 0.150 for Convergence (Shared Connectivity / Total Connectivity). 
Table 3

Configurations of Contextual Conditions Leading to Presence and Absence of Career Success Schema Complexity

Career Success Schema Complexity

\begin{tabular}{|c|c|c|c|c|c|}
\hline$\#$ & Configuration Pattern & Raw Coverage & Unique Coverage & Consistency & Countries Covered \\
\hline $\mathrm{c} 1.1$ & $\mathrm{HDI} \bullet \mathrm{EDUstd} \bullet \mathrm{IND} \bullet \mathrm{MAS}$ & .429 & .286 & 1 & Belgium, Italy, USA \\
\hline $\mathrm{c} 1.2$ & HDI • EDUstd $\bullet$ IND• Lmflex & .429 & .286 & 1 & France, Italy, Norway \\
\hline $\mathrm{c} 1.3$ & 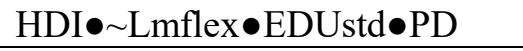 & .286 & .286 & 1 & Greece, Slovenia \\
\hline
\end{tabular}

\section{$\sim$ Career Success Schema Complexity}

\begin{tabular}{|c|c|c|c|c|c|}
\hline$\#$ & Configuration Pattern & Raw Coverage & Unique Coverage & Consistency & Countries Covered \\
\hline $\mathrm{c} 2.1$ & $\sim \mathrm{HDI} \bullet \sim \mathrm{IND} \bullet \mathrm{PD}$ & .833 & .833 & 1 & Brazil, China, India, Nigeria, Turkey \\
\hline $\mathrm{c} 2.2$ & $\sim$ Lmflex $\bullet \sim$ EDUstd $\bullet$ IND $\sim$ MAS $\bullet$ PD & .167 & .167 & 1 & South Korea \\
\hline
\end{tabular}

Notes. • Boolean AND (i.e., intersection); Boolean Negation (i.e., non-membership); Lmflex = Labor Market Flexibility; HDI = Human Development Index; EDUstd = Standardization of Educational System; MAS = Masculine Culture; PD = High Power Distance Culture; IND = Individualistic Culture. Intermediate solutions presented (assumptions for $\sim$ Complexity: HDI [absent], EDUstd [absent], IND [absent], MAS [absent]). The solution coverage and consistency is 1 for all outcomes. 
Table 4

Configurations of Contextual Conditions Leading to Presence and Absence of Career Success Schema Convergence

Career Success Schema Convergence

\begin{tabular}{|c|c|c|c|c|c|}
\hline$\#$ & Configuration pattern & Raw Coverage & Unique coverage & Consistency & Countries covered \\
\hline c3.1 & HDI•MAS & .571 & .429 & 1 & Belgium, Greece, Italy, USA \\
\hline c3.2 & HDI• Lmflex $\bullet \sim$ IND & .429 & .286 & 1 & Greece, South Korea, Slovenia \\
\hline c3.3 & HDI• Lmflex $\bullet \sim P D$ & .143 & .143 & 1 & Norway \\
\hline
\end{tabular}

Notes. $•$ Boolean AND (i.e., intersection); Boolean Negation (i.e., non-membership); Lmflex = Labor Market Flexibility; HDI = Human Development Index; EDUstd = Standardization of Educational System; MAS = Masculine Culture; PD = High Power Distance Culture; IND = Individualistic Culture. Intermediate solutions presented (assumptions for Convergence: HDI [present], EDUstd [present], IND [absent], PD [absent], LMflex [absent]). The solution coverage and consistency is 1 for all outcomes.

\section{$\sim$ Career Success Schema Convergence}

\begin{tabular}{llcccc}
\hline$\#$ & Configuration pattern & Raw Coverage & Unique coverage & Consistency & Countries covered \\
\hline c4.1 & $\sim$ HDI $\bullet$ PD & .833 & .833 & 1 & China, India, Turkey, Nigeria, Brazil \\
c4.2 & $\sim$ EDUstd $\bullet$ IND $\sim$ MAS $\bullet$ PD & .167 & .167 & 1 & France \\
\hline
\end{tabular}

Notes. • Boolean AND (i.e., intersection); Boolean Negation (i.e., non-membership); Lmflex = Labor Market Flexibility; HDI = Human Development

Index; EDUstd = Standardization of Educational System; MAS = Masculine culture; PD = High Power Distance; IND = Individualistic culture. Intermediate solutions presented (assumptions for Convergence: HDI [absent], EDUstd [absent], IND [present], PD [present], LMflex [present]). The solution coverage and consistency is 1 for all outcomes. 
Table 5

Career Success Schema (country-level) Archetypes with Configurations Depicting their Contextual Embeddedness

\begin{tabular}{|c|c|c|}
\hline & High Convergence & Low Convergence \\
\hline $\begin{array}{c}\text { High } \\
\text { Complexity } \\
\text { (Splitting) }\end{array}$ & 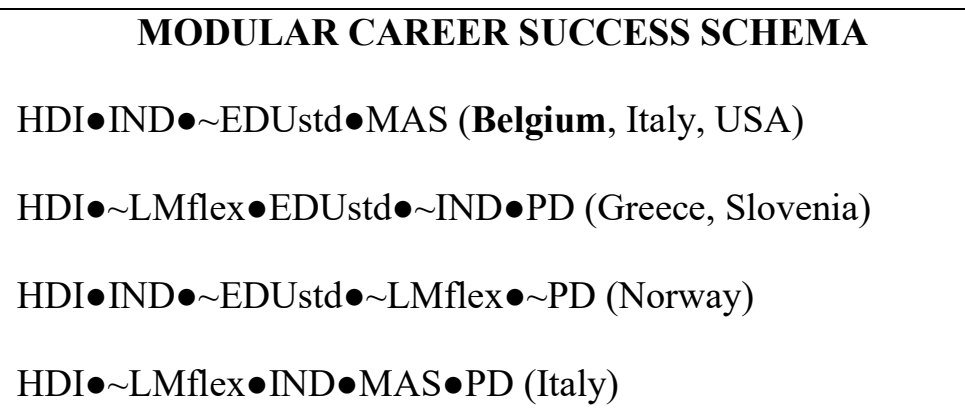 & 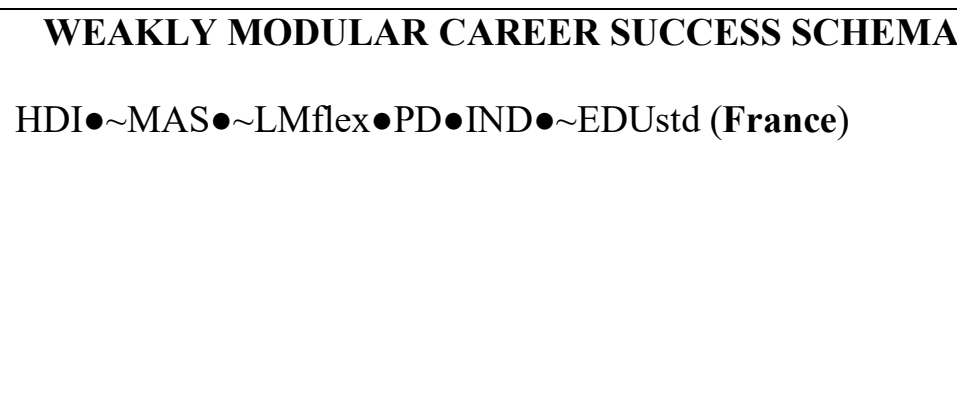 \\
\hline $\begin{array}{c}\text { Low } \\
\text { Complexity } \\
\text { (Lumping) }\end{array}$ & $\begin{array}{c}\text { HOLISTIC CAREER SUCCESS SCHEMA } \\
\text { HDI } \sim \mathrm{MAS} \bullet \sim \text { Lmflex } \bullet \mathrm{PD} \bullet \sim \mathrm{IND} \bullet \sim \text { EDUstd }(\text { South Korea })\end{array}$ & $\begin{array}{c}\text { DIFFUSED CAREER SUCCESS SCHEMA } \\
\sim \mathrm{HDI \bullet PD \bullet} \text { IND (China, India, Turkey, Brazil, Nigeria) }\end{array}$ \\
\hline
\end{tabular}

Notes. • Boolean AND (i.e., intersection); Boolean Negation (i.e., non-membership); Lmflex = Labor Market Flexibility; HDI = Human Development Index; EDUstd $=$ Standardization of Educational System; MAS = Masculine Culture; PD = High Power Distance Culture; IND = Individualistic Culture. Configuration(s) leading to a career success schema archetype is (are) listed in respective quadrants; example countries are indicated in parentheses; prototypical representative countries for each quadrant are in bold. 